\title{
Effect of extended period of boiling on allergic protein of flower tail shrimp Metapenaeus dobsoni
}

\author{
S. J. LALY ${ }^{1}$, T. V. SANKAR ${ }^{2}$ AND SATYEN KUMAR PANDA ${ }^{3}$ \\ ${ }^{1}$ Mumbai Research Centre of ICAR-Central Institute of Fisheries Technology, Vashi, Navi Mumbai - 400703 \\ Maharashtra, India \\ ${ }^{2}$ Kerala University of Fisheries and Ocean Studies, Kochi - 682 506, Kerala, India \\ ${ }^{3}$ ICAR-Central Institute of Fisheries Technology, P. O. Matsyapuri, Kochi - 682 029, Kerala, India \\ e-mail:lalyjawahar@gmail.com
}

\begin{abstract}
Consumption of shellfishes is a major cause of allergic reaction and $\operatorname{IgE}$ mediated hypersensitivity is an increasing health issue in sensitive individuals. Thermal stability of allergen of the flower tail shrimp Metapenaeus dobsoni was evaluated during extended period of boiling for immunoreactivity. Shrimp extracts boiled for 5 to 25 min showed increased IgE reactivity of 0.251 to $0.268 \mathrm{~nm}$ at absorbance of $490 \mathrm{~nm}$ in comparison to raw extract. Tropomyosin of $37 \mathrm{KDa}$ was observed to withstand longer periods of boiling and found to retain IgE binding activity. Thermal treatment by means of boiling for longer duration increased the recognition of this major allergen in individuals with shrimp sensitivity. Hence, tropomyosin subjected to longer period of boiling could be used in facilitating shrimp allergy diagnosis and for detection of allergen in processed food products.
\end{abstract}

Keywords: Boiling, IgE reactivity, Immunoblotting, Tropomyosin

\section{Introduction}

Seafoods are rich in many essential nutrients and can play a major role in the nutrition and health of human beings. Although consumers' preference of seafood is increasing, the major seafood groups such as fish and shellfish frequently cause allergic reactions in sensitive persons. Among shellfishes, shrimps are predominant in causing allergic reactions and IgE mediated shellfish allergy is a prevalent health issue in both children and adults (Tsabouri et al., 2012). Allergic reactions are usually associated with gastrointestinal and dermatological symptoms. It is also manifested with severe life threatening reactions like anaphylaxis and shellfish allergy is a long lasting one which can persist throughout life (Steensma, 2003; Lopata and Lehrer, 2009). The allergic symptoms can even develop in sensitive individuals due to inhalation of cooking vapours and direct handling contact with shellfish in addition to ingestion (Jeebhay and Lopata, 2012). It is reported that shellfish allergy patients have similarity with peanut allergy and show clinical reactivity throughout life associated with increased risk of wheezing and hyper reactivity (Lopata et al., 2010). Allergic responses in sensitive persons are mediated through immunoglobulin, IgE.

Myofibrillar protein, tropomyosin is reported as a major allergen in shellfishes having two identical subunits with molecular weight of 35 to $38 \mathrm{KDa}$ (Shanti et al., 1993; Leung et al., 1998). It is present in both muscle and non-muscle cells. It is an important muscle protein having major role in muscle contraction and is a pan allergen of invertebrates (Goetz and Whisman, 2000). Presence of this protein in very low concentration can elicit reactions in sensitive persons. Alpha helical and coiled structure of tropomyosin is highly conserved in nature and can cause IgE cross reactivity with patients allergic to crustaceans and house dust mites (Reese et al.,1999). The cross reactive nature of tropomyosin is reported to be due to highly conserved amino acid sequences (Lehrer et al., 2003). Although there is a number of IgE binding epitopes reported for tropomyosin, it can vary from one allergic person to another (Shanti et al., 1993; Motoyama et al., 2007). The allergenic protein structure in quaternary form can give stability enhancement through increasing IgE reactivity and by efficient antibody cross linking. Several other allergenic components other than tropomyosin have also been reported in shellfishes.

Avoidance of specific diet causing allergy is the main advice to people suffering from allergic reactions. Strict avoidance of specific diet can become difficult in situations with unintentional cross contact with different food materials and can result in allergic reactions in highly sensitive people. Accurate identification of allergic protein is highly essential for specific allergic testing 
and management of allergic patients. Allergenicity and allergen stability can be modified through different processing methods (Mondal et al., 2006; Abramovitch et al., 2017). Heat treatment in the form of boiling can enhance the texture and flavour along with microbiological safety. Protein denaturation due to loss in tertiary and/ or secondary interactions, new intra- or inter-molecular bonds, aggregation, rearrangements of disulfide bonds and other conformational modifications can ultimately lead to modification in allergen reactivity. As there is frequent reporting of shrimp allergic reactions, flower tail shrimp (Metapenaeus dobsoni), a commonly consumed shrimp species in Kerala, was selected to understand the effect of boiling on allergen potency. There is no previous report on changes in allergenicity during boiling for extended period of time of this locally consumed shrimp variety. The present study assessed the stability of allergen and how extended boiling alters the allergenicity of $M$. dobsoni.

\section{Materials and methods}

\section{Collection of shrimp samples and human sera}

Freshly landed samples of flower tail shrimp Metapeneaus dobsoni were collected from Kalamukku landing centre, Kochi. Samples were iced at 1:1 ratio and immediately transported to the laboratory in insulated boxes. The meat was collected, homogenised and stored at $-20^{\circ} \mathrm{C}$ until further analysis.

Blood samples $(10 \mathrm{ml})$ were collected from 13 patients with a history of immediate hypersensitive reaction and positive skin prick test to shrimp in general as per the record of Mary Queens Hospital, Allergy and Asthma Research Centre, Kochi, Kerala. The symptoms include breathlessness, diarrhea, vomiting, oral allergy syndrome, urticaria, swelling of face, hands and anaphylaxis. The persons hypersensitive to shrimps belonged to the age group between 20 and 58 years, comprising 8 females and 5 males. Blood samples were drawn from the patients with their consent for research purpose. Separation of individual sera was carried out by centrifuging at 2500 rpm for $20 \mathrm{~min}$ at $25^{\circ} \mathrm{C}$. Then sera from the patients were pooled and stored at $-20^{\circ} \mathrm{C}$. Sera from three healthy individuals with no allergic reaction to shrimp was also prepared on the same day and used as control. The control sera were also pooled and stored at $-20^{\circ} \mathrm{C}$.

\section{Preparation of boiled shrimp extracts}

Homogenised meat was extracted with four volumes of $0.01 \mathrm{M}$ phosphate buffered saline (PBS, $\mathrm{pH}$ 7.2) at $10000 \mathrm{rpm}$ for $10 \mathrm{~min}$ to prepare raw extract as per the method of Motoyama et al. (2007). Centrifugation was carried out at $8000 \mathrm{rpm}$ for $20 \mathrm{~min}$ and the supernatant was collected as raw extract. Five batches of the raw extract was kept in boiling water bath for time periods of 5,10 , 15,20 and 25 min respectively followed by centrifugation at $7500 \mathrm{rpm}$ for $10 \mathrm{~min}$ and the supernatant was collected. The protein concentration of the extracts was determined by Biuret method (Gornall et al., 1949) using bovine serum albumin (BSA) as standard. The prepared extracts were freeze dried and stored at $-20{ }^{\circ} \mathrm{C}$.

\section{Enzyme linked immunosorbent assay (ELISA)}

Enzyme linked immunosorbent assay (ELISA) was carried out as per the method reported by Ishikawa et al. (1997) using 96 well flat bottomed polystyrene microtitre plates. The plates were coated initially with $100 \mu \mathrm{l}$ of prepared extracts diluted with $0.05 \mathrm{M}$ carbonate buffer $(\mathrm{pH}$ $9.5)$ at $1: 1000$, which contained about $1 \mu \mathrm{g}$ protein. Then it was subjected to immunoreactions with $100 \mu \mathrm{l}$ of pooled serum from patient as well as control as primary antibody, diluted at 1:50 with $0.1 \%$ BSA in PBS. Subsequently, $100 \mu 1$ of secondary antibody i.e., HRP conjugated goat anti-human IgE antibody (Thermo Fisher Scienific) diluted at $1: 2500$ with $0.1 \%$ BSA in PBS was added. A substrate solution of $0.1 \%$ O-phynylenediamene dihydrochloride and $0.03 \%$ hydrogen peroxide in $0.05 \mathrm{M}$ phosphate-citrate buffer at $\mathrm{pH} 5$ was added to effect the enzymic reaction for a period of $30 \mathrm{~min}$ at room temperature and the reaction was terminated using $2 \mathrm{~N} \mathrm{H}_{2} \mathrm{~S}_{4}$. The resulting colour was measured at $490 \mathrm{~nm}$ using microplate reader. Each of the analyses was carried out in triplicate and the results expressed as mean \pm standard error.

\section{SDS-PAGE and immunoblotting}

Sodium dodecyl sulphate polyacrylamide gel electrophoresis (SDS-PAGE) was carried out as per the method reported by Laemmli (1970) using Mini Protean 3 Apparatus (Bio-Rad, USA). The separating and stacking gels used were of 12 and $4 \%$ polyacrylamide $(30 \% \mathrm{~T})$ respectively. It was run at $150 \mathrm{~V}$ for $50-60 \mathrm{~min}$. The shrimp extracts were mixed with Lamelli buffer in the ratio of $1: 4$, heated at $95^{\circ} \mathrm{C}$ for $4 \mathrm{~min}$, cooled and loaded along with a wide range protein marker (Sigma) as a reference. Shrimp extracts were loaded at $10 \mu \mathrm{g}$ per lane in wells $1,2,3,4$ and 5 and $15 \mu \mathrm{g}$ per lane in $\mathrm{R}$ for separation by electrophoresis. After completion of running, the gels were stained with Coomassie blue R-250 and de-stained using acetic acid (7\%) solution. Relative molecular weights of bands were determined based on protein bands of marker.

Then the proteins were electrophoretically transferred to a $0.45 \mu \mathrm{m}$ nitrocellulose membrane using Mini TransBlot System (Bio-Rad, USA) at $80 \mathrm{~V}$ for $120 \mathrm{~min}$. The membrane was washed with $0.05 \%$ Tween 20 in Tris Buffered Saline (TBS) and blocked using 3\% BSA (w/v) in TBS. Then it was subjected to reaction with pooled 
patients' sera (diluted 1:50 in blocking buffer) at $4^{\circ} \mathrm{C}$ overnight. The membrane was then subjected to reaction with HRP conjugated goat anti-human IgE antibody (ThermoFisher Scienific) diluted at $1: 500$ at $37^{\circ} \mathrm{C}$ for $1 \mathrm{~h}$. The membrane was then incubated with colourimetric horse radish peroxidase (HRP) substrate using Opti-4CN substrate kit (Bio-Rad, USA).

\section{$2 D$ gel electrophoresis and immunoblotting}

Two dimensional gel electrophoresis (2-DE) was carried out as per the method given by Vinod et al. (2018). An amount of $200 \mu \mathrm{g}$ of boiled sample was made upto $125 \mu \mathrm{l}$ using rehydration buffer having a final concentration of $7 \mathrm{M}$ urea, 2 Mthiourea, 2\% DTT, 2\% ASB-14-4, 4\% CHAPS, $0.001 \%$ bromophenol blue and 2\% ampholyte ( $\mathrm{pH} 3-10)$. Then the sample was loaded to $7 \mathrm{~cm}$ IPG strip holder, overlaid with IPG strip, covered with $700 \mu$ l of mineral oil and rehydrated actively (50 V, 201C) for $18 \mathrm{~h}$ using IEF cell. Filter wicks were hydrated and placed under the gel after rehydration. DTT of $600 \mathrm{mM}$ was used for hydrating cathodic filter wick, whereas water was used for anodic filter wick. IEF was carried out at $300 \mathrm{~V}$ for $30 \mathrm{~min}$, $1000 \mathrm{~V}$ (gradient) for $30 \mathrm{~min}, 5000 \mathrm{~V}$ (gradient) for 1.5 $\mathrm{h}$ and continued at $5000 \mathrm{~V}$ for another $30 \mathrm{~min}$. Then it was held at $50 \mathrm{~V}$ for $12 \mathrm{~h}$. In continuation to this, the IPG strip was subjected to incubation in equilibration buffer I (50 mM Tris, pH 8.8, $6 \mathrm{M}$ urea, 30\% glycerol, 2\% SDS) with $0.3 \%$ DTT for $10 \mathrm{~min}$ followed by incubation in equilibration buffer II having 4.5\% iodoacetamide for 10 $\min$.

Equilibrated IPG strip was kept on 12\% SDS-PAGE gel and sealed using agarose buffer $(0.75 \%$ agarose in $1 \mathrm{M}$ Tris glycine, SDS buffer containing $0.003 \%$ bromophenol blue). After separation of proteins in the SDS-PAGE gel, they were electrophoretically transferred to nitrocellulose membrane as per the above procedure. The protein bands were visualised in the membrane using ponceau $\mathrm{S}$ stain (Genetix Biotech Asia Pvt. Ltd., New Delhi), de-stained and immunoblotted using pooled sera of shrimp allergic patients.

\section{Results and discussion}

\section{IgE binding ability of boiled extracts}

Raw extract of $M$. dobsoni was subjected to boiling at durations of 5, 10, 15, and 20 and $25 \mathrm{~min}$ and $\operatorname{IgE}$ binding ability was evaluated by ELISA method (Fig. 1). Pooled allergic patients' sera exhibited significantly $(\mathrm{p}<0.05)$ higher IgE binding ability to boiled extracts in comparison to raw extract. No significant difference $(p>0.05)$ in $\operatorname{IgE}$ activity was observed between shrimp extracts boiled for different time periods.

The raw extract exhibited an IgE binding ability of $0.212 \pm 0.01$ at absorbance of $490 \mathrm{~nm}$. The extracts boiled for 5 to 25 min showed $\operatorname{IgE}$ binding ability ranging from 0.251 to $0.268 \mathrm{~nm}$ at absorbance of $490 \mathrm{~nm}$. Cooking or thermal process can enhance allergenicity due to different mechanisms like protein denaturation, formation of new epitopes, aggregation and chemical modification (Clare Mills et al., 2009). Ebo and Stevens (2001) reported that food allergens will be highly resistant to denaturation and can elicit immune reaction even under conditions of heating and enzymatic action. Abramovitch et al. (2013) reported higher $\operatorname{IgE}$ reactivity in case of cooked extracts of blue swimmer crab and black tiger shrimp. Increased IgE reactivity of the cooked crustacean extracts due to modification of crustacean protein as a result of glycation during heating has been reported (Abramovitch et al., 2017). Heating can also modify conformation of proteins and hence allergenicity by disrupting disulfide bonds. The conformational changes can lead to better epitope recognition by antibody after heating (Albrecht et al., 2009).

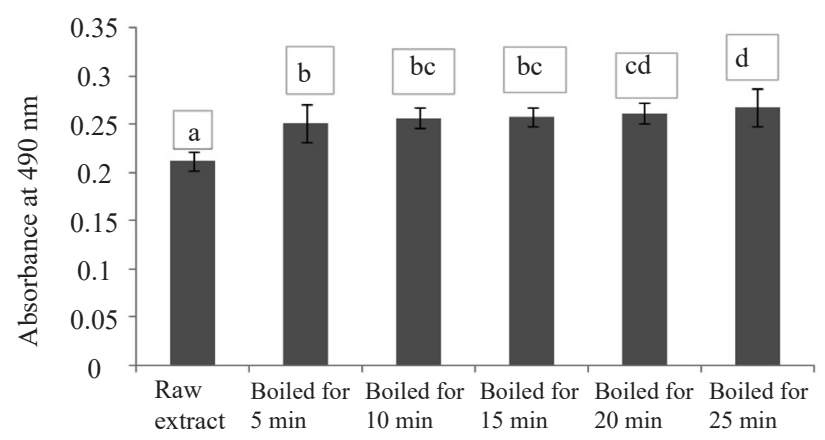

Fig. 1. IgE reactivity of raw extract and extract boiled for different duration. Bars with different alphabets indicate significant difference

\section{SDS-PAGE analysis of raw and boiled extracts}

As cooking in the form of boiling can give a thermal treatment effect, changes on allergic protein can be observed in SDS PAGE pattern. The SDS-PAGE pattern of raw and boiled extracts at different time durations are given in Fig. 2. In case of raw extract, a number of bands ranging between 205 and $6.5 \mathrm{KDa}$ were observed. In case of boiled extracts, many protein bands were absent in comparison to raw extracts. Tropomyosin of $37 \mathrm{KDa}$, the reported major allergen in shellfishes was found to be conserved in all the boiled extracts, regardless of the duration of boiling from 5 to $25 \mathrm{~min}$. Remarkable reduction of protein bands in boiled extracts between 205 and $45 \mathrm{KDa}$ were observed in comparison to raw extract. The loss of protein bands in all the boiled extracts may be related to the effects of heat. Thermal treatment can cause potential modifications in the proteins including fragmentation, denaturation, or intra- or inter-molecular protein cross linking (Taheri-Kafrani et al., 2009; Oliveira et al., 2013). Even during extended boiling period upto $25 \mathrm{~min}$, the protein profile pattern was not altered (Fig. 2). 
The formation of advanced glycation end products after heating in the presence of endogenous or exogenous sugars by the Maillard reaction can increase IgE binding which is reported in other food allergens (Ilchmann et al., 2010).

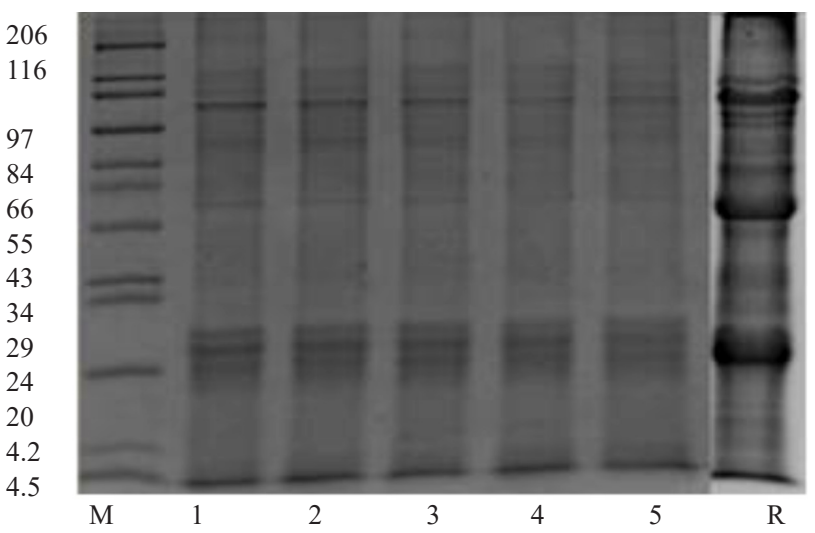

Fig. 2. SDS PAGE analysis of raw and boiled extracts. M - Molecular weight marker, Line 1- Boiled extract (5 min.), Line 2 - Boiled extract (10 min.), Line 3 - Boiled extract (15 min.), Line 4 - Boiled extract (20 min.), Line 5 - Boiled extract (25 min.), R - Raw extract.

\section{Immunoblotting}

Immunoblotting of all the boiled extracts at different time duration with pooled sera of allergic patients showed IgE binding at $37 \mathrm{KDa}$ (Fig. 3). Intense and thick dark bands were observed at $37 \mathrm{KDa}$ for cooked extracts of M. dobsoni with individual patient sera in a previous study (Laly et al., 2019). IgE binding components observed at $20 \mathrm{KDa}$ and $75 \mathrm{KDa}$ (line 2 and 3 of Fig. 3) are less intense and are minor allergens. After heat treatment by means of boiling, tropomyosin showed strong $\operatorname{IgE}$ binding due to recognition by pooled sera of shrimp allergic patients.

This finding again confirmed and proved that tropomyosin is heat resistant in nature and can retain IgE-binding ability even after prolonged heating period (Leung et al., 1998; Motoyama et al., 2007; Kamath et al., 2013). Reese et al. (1999) reported that tropomyosin can withstand heat-treatment by most known type of food processing techniques and it could be specifically due to its exceptionally stable alpha helical coiled secondary structure. Tropomyosin subjected to boiling can undergo protein-protein interactions or aggregations during thermal treatment and can result in enhanced IgE binding (Mine and Yang, 2008).

\section{$2 D$ immunoblotting}

Extract of flower tail shrimp boiled for $15 \mathrm{~min}$ was separated by 2D electrophoresis and subjected to immunoblotting with pooled sera of shrimp sensitive persons (Fig. 4). Protein spots were identified in the molecular weight

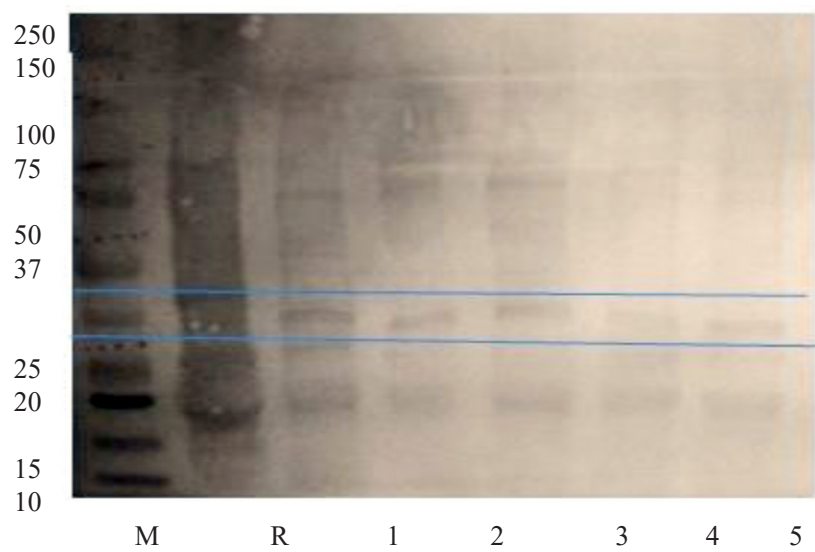

Fig. 3. Immunoblot analysis of raw and boiled extracts. M - Molecular weight marker, R - Raw extract, Line 1- Boiled extract (5 min.), Line 2 - Boiled extract (10 min.), Line 3 - Boiled extract (15 min.), Line 4 - Boiled extract (20 min.), Line 5 Boiled extract (25 min.)

range of 50 to $20 \mathrm{KDa}$ (Fig. 4a). During immunoblotting of boiled extract, a prominent band at approximately $37 \mathrm{KDa}$ protein was identified clearly in presence of pooled sera of shrimp sensitive persons (Fig. 4b). Tropomyosin of 37 $\mathrm{KDa}$ was identified as the major allergen by individual shrimp allergy patient sera in flower tail shrimp earlier (Laly et al., 2019). Yadzir et al. (2015) reported the allergic protein of carpet clam by 2D immunoblotting. Alteration in the protein structure by boiling can lead to destruction or modification of epitope and affect IgE binding (Paschke and Besler, 2002). In the native configuration, tropomyosin exists in the form of dimers. The structural speciality of the molecule can enhance stability and $\operatorname{IgE}$ reactivity by cross linking with the antibody. Yang et al. (2010) and Gamez et al. (2011) reported that the best single molecular marker for evaluating the clinical symptoms of crustacean allergy is shrimp tropomyosin specific $\operatorname{IgE}$.

Understanding shrimp allergenicity during thermal treatment by means of cooking or boiling is important as it is a common household culinary method. Allergenic properties of shrimp during extended period of boiling are critical for shrimp sensitive individuals. Higher IgE reactivity was observed for extracts of flower tail shrimp boiled for 5 to 25 min. Trpomyosin of $37 \mathrm{KDa}$ was observed to withstand longer periods of boiling and found to retain IgE binding activity, by SDS PAGE and by 1D/2D immunoblotting, respectively. Thermal treatment by means of boiling for longer duration increased the recognition of this major allergen in individuals with shrimp sensitivity. Hence tropomyosin subjected to longer period of boiling could be used in facilitating shrimp allergy diagnosis and for detection of allergen in processed food products to protect consumers with high sensitivity. 

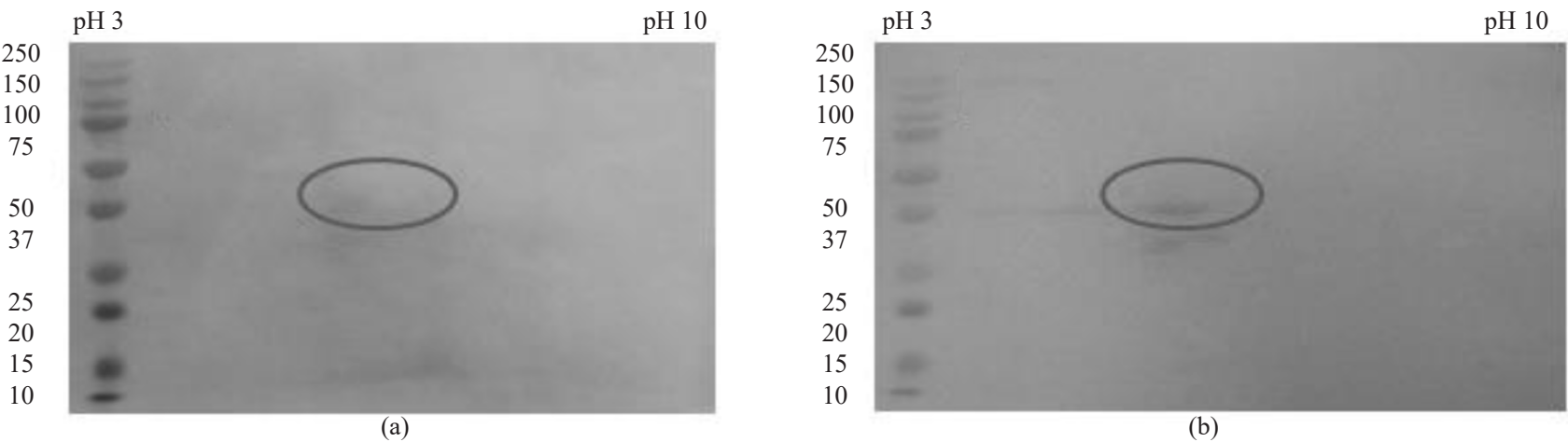

Fig. 4. Two dimensional gel electrophoresis and immunoblot analysis of boiled extract (15 min.) of flower tail shrimp (M. dobsoni). (a) Ponceau S stained image, (b) 2D immunoblot with pooled patient sera. M - Molecular weight marker

\section{Acknowledgements}

This research work was carried out with the support of ICAR, New Delhi, India. The authors sincerely thank the Director, ICAR-CIFT, Kochi for providing facilities and support to undertake this work.

\section{References}

Abramovitch, J. B., Kamath, S. and Varese, N. 2013. IgE reactivity of blue swimmer crab (Portunus pelagicus) Tropomyosin, Por $\mathrm{p} 1$, and other allergens; cross-reactivity with black tiger prawn and effects of heating. PLoS One, 8 (6): e67487. DOI:10.1371/journal.pone.0067487.

Abramovitch, J. B., Lopata, A. L. O’Hehir, R. E. and Rolland, J. M. 2017. Effect of thermal processing on $\mathrm{T}$ cell reactivity of shellfish allergens - Discordance with IgE reactivity. PLoS One. 12(3), e0173549. doi:10.1371/ journal.pone.0173549. eCollection 2017.

Albrecht, M., Kuhne, Y., Ballmer-Weber, B. K. and Becker, W. M. 2009. Relevance of IgE binding to short peptides for the allergenic activity of food allergens. J. Allergy Clin. Immunol., 124, 328-336. . doi: 10.1016/j.jaci.2009.05.031. Epub 2009 Jul 12.

Clare Mills, E. N., Sancho, A. I., Rigby, N. M., Jenkins, J. A. and Mackie, A.R. 2009. Impact of food processing on the structural and allergenic properties of food allergens. Mol. Nutr. Food Res., 53: 963-969 doi: 10.1002/mnfr.200800236.

Ebo, D. and Stevens, W. 2001. IgE mediated food allergy: extensive review of the literature. Acta Clinica Belgica, 56(4): 234-247. DOI:10.1179/acb.2001.035.

Gamez, C., Sanchez-Garcia, S., Ibanez, M. D. and Lopez, R. 2011. Tropomyosin IgE-positive results are a good predictor of shrimp allergy. Allergy, 66: 1375-1383. doi: 10.1007/ s40629-016-0124-2.

Goetz, D. W. and Whisman, B. A. 2000. Occupational asthma in a seafood restaurant worker: cross-reactivity of shrimp and scallops. Ann. Allergy Asthma Immunol., 85: 461-466. DOI:10.1016/S1081-1206(10)62572-0.
Ilchman, A., Burdorf, S., Scheuer, S., Waibler, Z., Nagai, R., Wellner, A., Yamamoto, Y., Yamamoto, H., Henle, T., Kurts, C., Kalinke, U., Vieths, S. and Toda, M. J. 2010. Glycation of a food allergen by the Maillard reaction enhances its $\mathrm{T}$ cell immunogenicity: Role of macrophage scavenger receptor class A type I and II. J. Allergy Clin. Immunol., 125(1): 175-83.e1-11.

Ishikawa, M., Shimakura, K., Nagashima, Y. and Shiomi, K. 1997. Isolation and properties of allergenic proteins in the oyster Crassostrea gigas. Fish. Sci., 63: 610-614. https://doi.org/10.2331/fishsci.63.610.

Jeebhay, M. F. and Lopata, A. L. 2012. Occupational allergies in seafood processing workers. Adv. Food Nutr. Res., 66 : 47-73. doi: 10.1016/B978-0-12-394597-6.00002-1.

Kamath, S. D., Abdel Rahman, A. M., Komoda, T. and Lopata, A. L. 2013. Impact of heat processing on the detection of the major shellfish allergen tropomyosin in crustaceans and molluscs using specific monoclonal antibodies. Food Chem., 141(4): 4031-9. DOI:10.1016/j. foodchem.2013.06.105.

Laemmli,U.K. 1970 Cleavage of structural proteins during the assembly of the head of bacteriophageT4. Nature, 227: 680 - 685.

Laly, S. J., Sankar, T. V. and Satyen Kumar Panda. 2019. Identification of allergic proteins of flower tail shrimp (Metapenaeus dobsonii), J. Food Sci. Technol., DOI 10.1007/s13197-019-04012-0.

Lehrer, S. B., Ayuso, R. and Reese, G. 2003. Seafood allergy and allergens: a review. Mar. Biotechnol., 5(4): 339-348. DOI: 10.1007/s10126-002-0082-1.

Leung, P. S. C., Chen, Y. C., Gershwin, M. E., Wong, S. H., Kwan, S. H. and Chu, K. H. 1998. Identification and molecular characterization of Charybdis feriatus tropomyosin, the major crab allergen. J. Allergy Clin. Immunol., 102(5): 847-852. doi: 10.2147/JAA.S142476.

Lopata, A. L., O'Hehir, R. E. and Lehrere, S. B. 2010. Shellfish allergy. Clin. Exp. Allergy, 40: 850-858.

Lopata, A. L. and Lehrer, S. B. 2009. New insights into seafood allergy. Curr. Opin. Allergy Clin. Immunol., 9: 270-277. 
Mine, Y. and Yang, M. 2008. Recent advances in the understanding of egg allergens: basic, industrial and clinical perspectives. J. Agric. Food Chem., 56(13): 4874-900. DOI:10.1021/ jf8001153.

Motoyama, K., Suma, Y., Ishizaki, S., Nagashima, Y. and Shiomi, K. 2007. Molecular cloning of tropomyosins identified as allergens in six species of shellfishes. J. Agric. Food Chem., 55(3): 985-91. DOI:10.1021/jf062798x.

Paschke, A. and Besler, M. 2002. Stability of bovine allergens during food processing. Ann. Allergy Asthma Immunol., 89(1): 16-20.

Reese, G., Ayuso, R. and Lehrer, S. B. 1999. Tropomyosin: an invertebrate pan-allergen. Int. Arch. Allergy Immunol., 119: 247-258. DOI:10.1159/000024201.

Shanti, K. N., Martin, B. M., Nagpal, S., Metcalfe, D. D. and Rao, P. V. 1993. Identification of tropomyosin as the major shrimp allergen and characterization of its IgE-binding epitopes. J. Immunol., 151(10): 5354-5363.

Steensma, D. P. 2003. The kiss of death: a severe allergic reaction to a shellfish induced by a good-night kiss. Mayo Clin. Proc., 78: 221-222. DOI:10.4065/78.2.221.

Taheri-Kafrani, A., Gaudin, J. C., Rabesona, H., Nioi, C., Aqarwal, D. and Drouet, M. 2009. Effects of heating and glycation of beta-lactoglobulin on its recognition by IgE of sera from cow milk allergy patients. J. Agric. Food Chem., 57(11): 4974-82. DOI:10.1021/jf804038t.

Tsabouri, S., Triga, M., Makris, M., Kalogeromitros, D., Church, M. K. and Priftis, K. N. 2012. Fish and shellfish allergy in children: Review of a persistent food allergy. Pediatr. Allergy Immunol., 23: 608-615. https://doi.org/10.1111/ j.1399-3038.2012.01275.x.

Vinod, S. P., Rameshwari, R. K., Fabia, E., Sreepriya, N., Jai, T., Roshini, A. M., Tessy, X., Padmanabha, S. and Krishnakumar, N. M. 2018. Identification of prolargin expression in articular cartilage and its significance in rheumatoid arthritis pathology. Int. J. Biol. Macromol., 110: 558-566. doi: 10.1016/j.ijbiomac.2018.01.141.

Yadzir, H. A. M., Misnan, R., Bakhtiar, F., Abdullah, N. and Murad, S. 2015. Tropomyosin and actin identified as major allergens of the carpet clam (Paphia textile) and the effect of cooking on their allergenicity. Biomed. Res. Int., Article ID: 254152. http://dx.doi.org/10.1155/2015/254152.

Yang, A. C., Arruda, L. K., Santos, A. B. R. and Barbosa, M. C. R. 2010. Measurement of IgE antibodies to shrimp tropomyosin is superior to skin prick testing with commercial extract and measurement of $\operatorname{IgE}$ to shrimp for predicting clinically relevant allergic reactions after shrimp ingestion. J .Allergy Clin. Immunol., 125: 872-878. DOI:10.1016/j. jaci.2009.11.043. 